\title{
Development of an international comorbidity education framework
}

\author{
C. Lawson ${ }^{\mathrm{a}, *}$, S. Pati ${ }^{\mathrm{b}, *}$, J. Green ${ }^{\mathrm{c}}$, G. Messina ${ }^{\mathrm{d}}$, A. Strömberg ${ }^{\mathrm{e}}$, N. Nante ${ }^{\mathrm{d}}$, D. Golinelli ${ }^{\mathrm{d}}$,

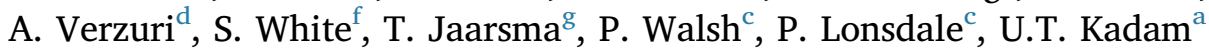 \\ a Keele University, Keele Cardiovascular Research Group, Institute of Applied Clinical Sciences, UK \\ b Public Health Foundation of India, Indian Institute of Public Health-Bhubaneswar, India \\ c Keele University, Department of Nursing and Midwifery, UK \\ ${ }^{\mathrm{d}}$ University of Siena, Department of Public Health, Italy \\ e Linkoping University, Medical and Health Sciences, Sweden \\ ${ }^{\mathrm{f}}$ Keele University, Department of Pharmacy, UK \\ ${ }^{\mathrm{g}}$ Linkoping University, Social and Welfare Studies, Sweden
}

\section{A R T I C L E I N F O}

\section{Keywords:}

Comorbidity

Multimorbidity

Health

Curriculum

Education

\begin{abstract}
A B S T R A C T
Context: The increasing number of people living with multiple chronic conditions in addition to an index condition has become an international healthcare priority. Health education curricula have been developed alongside single condition frameworks in health service policy and practice and need redesigning to incorporate optimal management of multiple conditions.

Aim: Our aims were to evaluate current teaching and learning about comorbidity care amongst the global population of healthcare students from different disciplines and to develop an International Comorbidity Education Framework (ICEF) for incorporating comorbidity concepts into health education.

Methods: We surveyed nursing, medical and pharmacy students from England, India, Italy and Sweden to evaluate their understanding of comorbidity care. A list of core comorbidity content was constructed by an international group of higher education academics and clinicians from the same disciplines, by searching current curricula and analysing clinical frameworks and the student survey data. This list was used to develop the International Comorbidity Education Framework.

Results: The survey sample consisted of 917 students from England (42\%), India (48\%), Italy (8\%) and Sweden $(2 \%)$. The majority of students across all disciplines said that they lacked knowledge, training and confidence in comorbidity care and were unable to identify specific teaching on comorbidities. All student groups wanted further comorbidity training. The health education institution representatives found no specific references to comorbidity in current health education curricula. Current clinical frameworks were used to develop an agreed list of core comorbidity content and hence an International Comorbidity Education Framework.

Conclusions: Based on consultation with academics and clinicians and on student feedback we developed an International Comorbidity Education Framework to promote the integration of comorbidity concepts into current healthcare curricula.
\end{abstract}

\section{Introduction}

Globally populations are living longer, which means people are often living with two or more conditions; this issue has become an international healthcare priority (OECD, 2011). A conceptual distinction is drawn between 'comorbidity' and 'multimorbidity' (Van der Akker et al., 1996). The term multimorbidity is used when the focus is on the implications that having multiple conditions has for patients' self-management and for delivery of healthcare generally. The term comorbidity is used when the focus is on how other conditions may influence the management of an index condition. Internationally, most healthcare systems are based on single condition frameworks (Lugtenberg et al., 2011) and undergraduate and postgraduate training is organised in terms of holistic care or the management of single conditions. There is a clear evidence gap for education and training on how quality and standards of care for each of the single conditions can be integrated to form the optimal chronic disease and other conditions management to improve the overall care of the patient (Salisbury, 2012; Anderson, 2011). This is a critical issue as people with comorbidities often experience fragmented care (Burgers et al., 2010) and

\footnotetext{
* Corresponding authors.

E-mail address: c.a.lawson@keele.ac.uk (C. Lawson).
} 
face worse outcomes in terms of quality of life, morbidity and mortality (Rushton and Kadam, 2014; Rushton et al., 2015a; Pati et al., 2014; Stewart et al., 2016). Care that ignores comorbidities can be irrelevant or harmful (Boyd et al., 2005; Tinetti et al., 2004; Ferguson et al., 2016). Comorbidity thus presents a major challenge to healthcare policy and higher education institutions across the world.

Most health education institutions are hospital-centric, with the result that students of nursing, medicine and other health professions spend much of their training in specialist clinical environments (Anderson, 2011). This approach, which is a legacy of the infectious disease and acute illness era, does not lend itself to integrating theoretical teaching with practical learning about prevention or management of chronic conditions, as such conditions are often managed in the community. In the case of management of people with multiple chronic conditions, the mismatch between theory and practice is compounded by reliance on condition-specific evidence and treatment guidelines that seldom include any specific guidance on comorbidities (Lugtenberg et al., 2011). Consequently single condition approaches dominate medical education (OECD, 2011; Yardley et al., 2015; Barnett et al., 2012) and all other healthcare disciplines (Rushton et al., 2015b). Nursing, despite its holistic roots, is increasingly organised around condition-targeted specialist roles and this means that nurses are less competent to deal with the complex needs of people with comorbidities or provide person-centred care (Castledine, 2006). The increasing number of people with multiple conditions also means that prescribers need enhanced skills (King's Fund, 2013). Specialisation has come to dominate healthcare, education and training, and there are few examples of specific education in dealing with comorbidity. A clear illustration of this is the separation of mental and physical health in healthcare curricula (Blythe and White, 2012).

Frameworks have been developed for addressing comorbidities within healthcare systems (Department of Health, 2014) and for individualised care (American Geriatrics Society, 2012) but, to our knowledge, there are currently no educational frameworks or tools that integrate knowledge about comorbidities into healthcare curricula. As lack of comorbidity training is common to multiple healthcare disciplines and potentially across the world, we wanted to develop a framework for comorbidity education that could be used in multiple disciplines, in interdisciplinary training and in various international contexts.

\section{Aims and Objectives}

We aimed to evaluate current training about comorbidities in several health disciplines across several countries and to develop an International Comorbidity Education Framework (ICEF) that could be used to integrate comorbidity care principles into current healthcare curricula.

Our objectives were as follows.

(i) To explore the students' perceptions of their knowledge, skills and confidence in relation to comorbidity care and to assess their opinions of how well comorbidity was covered in their courses using self-report questionnaires. We surveyed students of nursing, medicine and pharmacy from several countries.

(ii) To assess comorbidity content in current healthcare curricula by consulting a group of clinicians and healthcare academics from four countries (England, Sweden, Italy and India) and to use this information, together with the student survey data and clinical frameworks to produce a core list of comorbidity content.

(iii) To use the core list of comorbidity content to develop an International Comorbidity Education framework (ICEF).

\section{Ethical Approval}

The study was reviewed by a university research ethics committee who deemed that formal approval was not required. Ethical procedures were used throughout the study. Students were fully informed about the purpose of the survey and participation was voluntary. All survey data were anonymised prior to analysis.

\section{Methods}

\subsection{Student Survey}

We used a structured questionnaire to assess nursing, medical and pharmacy students' understanding of multimorbidity and comorbidity. Students were presented with three scenarios of increasing complexity. Patient A had a single index condition, patient $B$ had an index condition and a comorbidity and patient $C$ had several comorbidities in addition to the index condition (Supplementary File A). The students were asked whether their knowledge, training and confidence were sufficient to provide care for these patients. Students were also asked to identify any comorbidity-related topics in their training programmes and as well as additional topics that might facilitate their understanding about care of a person with comorbidities. The questionnaires were administered to convenience samples of students of nursing, medicine and pharmacy in England, Sweden, Italy and India. The English language version of the survey was administered to students from England, India and Sweden and an Italian translation was used with students from Italy.

\subsection{Comorbidity Curriculum Content}

We set up a core international group of health education institution representatives, comprising heads of schools from the three disciplines, to explore current curricula and gaps. All four organisations from the different countries and respective disciplines were asked to review current curricula to identify where comorbidity was included. We then conducted two health education institution workshops in England and Sweden and held face-to-face and video conference meetings in Italy and India respectively. The purpose of the workshops and meetings was to use current clinical frameworks (Department of Health, 2014; American Geriatrics Society, 2012), the student survey data and current curricula to construct a list of core comorbidity content to be included in health curricula. The draft list was circulated for editing. The goal was to produce an agreed final list that would be relevant to all disciplines in all countries.

\subsection{ICEF Development}

To produce an educational framework that could be used across the health disciplines and applied to the wide range of different learning and teaching modalities (lectures, case or problem based learning, reflective portfolios, practice case management and clinical scenarios or e-learning activities) we organised the core content in terms of six comorbidity concepts. Feedback on the draft framework was obtained from a sample of English nursing students using a structured questionnaire and the framework was adapted where necessary. Finally, the framework was discussed and amended by health education institution groups from the four countries to produce a consensus version.

\section{Results}

\subsection{Socio-demographic Characteristics}

The survey sample comprised 917 students (nursing $n=522$; medicine $n=344$; pharmacy $n=51$ ). The sample was drawn from England (42\%), India (48\%), Italy (8\%) and Sweden (2\%) (Fig. 1). The English subsample included more mature student (age over 30 years) nurses (19\%) than the Indian (6\%), Italian (2\%) and Swedish (10\%) subsamples. India had the lowest proportion of male nursing student responders (5\%). In India and Italy all medical student responders were 
Table 2

Student survey responses to cases.

\begin{tabular}{|c|c|c|c|c|c|c|c|c|c|c|c|}
\hline \multirow[t]{3}{*}{$(\mathrm{N})$} & \multirow[t]{3}{*}{ Student discipline } & \multicolumn{3}{|l|}{ Case A } & \multicolumn{3}{|l|}{ Case B } & \multicolumn{3}{|l|}{ Case C } & \multirow{3}{*}{$\begin{array}{l}\text { More training } \\
\text { More training? } \\
\text { Yes (\%) } \\
\text { N (\%) }\end{array}$} \\
\hline & & \multicolumn{3}{|l|}{ Case A } & \multicolumn{3}{|l|}{ Case B } & \multicolumn{3}{|l|}{ Case C } & \\
\hline & & $\begin{array}{l}\text { Knowledge } \\
\text { N (\%) }\end{array}$ & $\begin{array}{l}\text { Training } \\
\mathrm{N}(\%)\end{array}$ & $\begin{array}{l}\text { Confidence } \\
\mathrm{N}(\%)\end{array}$ & $\begin{array}{l}\text { Knowledge } \\
\text { N (\%) }\end{array}$ & $\begin{array}{l}\text { Training } \\
\mathrm{N}(\%)\end{array}$ & $\begin{array}{l}\text { Confidence } \\
\mathrm{N}(\%)\end{array}$ & $\begin{array}{l}\text { Knowledge } \\
\text { N (\%) }\end{array}$ & $\begin{array}{l}\text { Training } \\
\mathrm{N}(\%)\end{array}$ & $\begin{array}{l}\text { Confidence } \\
\mathrm{N}(\%)\end{array}$ & \\
\hline \multirow[t]{3}{*}{ All } & Nursing (502) & $265(51.4)$ & $246(47.9)$ & $283(55)$ & $225(43.7)$ & $191(37.2)$ & $220(43.1)$ & 164 (31.9) & $152(29.5)$ & $168(32.9)$ & 468 (95.5) \\
\hline & Medicine (344) & $178(53.5)$ & $164(48.8)$ & $125(37.5)$ & $155(46.6)$ & $123(37.1)$ & $115(35.2)$ & $111(33.7)$ & $95(28.7)$ & $89(27.1)$ & $277(86.8)$ \\
\hline & Pharmacy (51) & $35(68.6)$ & $29(56.9)$ & $26(52)$ & $27(56.2)$ & $21(43.8)$ & $19(39.6)$ & $14(43.8)$ & $15(31.3)$ & $12(25)$ & $40(95.2)$ \\
\hline \multirow[t]{2}{*}{ UK } & Nursing (341) & $111(32.9)$ & $109(32.6)$ & $138(40.9)$ & $90(26.8)$ & 65 (19.5) & $80(24)$ & $49(14.6)$ & $43(12.8)$ & $49(14.7)$ & $312(98.1)$ \\
\hline & Pharmacy (51) & $35(68.6)$ & $29(56.9)$ & $26(52)$ & $27(56.2)$ & $21(43.8)$ & $19(39.6)$ & $14(43.8)$ & $15(31.3)$ & $12(25)$ & $40(95.2)$ \\
\hline \multirow[t]{2}{*}{ India } & Nursing (116) & $102(88.8)$ & $94(82.4)$ & $94(84)$ & $94(82.5)$ & $91(79.8)$ & $88(77.9)$ & $82(71.3)$ & $79(68.7)$ & $87(77.7)$ & $106(99.1)$ \\
\hline & Medicine (317) & $163(52.7)$ & $154(49.4)$ & $115(37.2)$ & $142(46.1)$ & $114(37.1)$ & $101(33.1)$ & $103(33.8)$ & $93(30.4)$ & $86(28.3)$ & $254(86.1)$ \\
\hline \multirow[t]{2}{*}{ Italy } & Nursing (45) & $33(73.4)$ & $28(63.2)$ & $33(73.3)$ & $27(60)$ & $25(55.6)$ & $40(88.9)$ & $20(45.5)$ & $17(37.8)$ & $19(42.2)$ & 31 (68.9) \\
\hline & Medicine (27) & $15(62.5)$ & $10(41.7)$ & $10(41.6)$ & $13(54.2)$ & $9(37.5)$ & $14(63.6)$ & $8(33.4)$ & $2(8.4)$ & $3(12.5)$ & $23(95.8)$ \\
\hline Sweden & Nursing (20) & $19(95)$ & $15(75)$ & $18(90)$ & $14(70)$ & $10(50)$ & $12(60)$ & $23(65)$ & $13(65)$ & $13(65)$ & 19 (95) \\
\hline
\end{tabular}

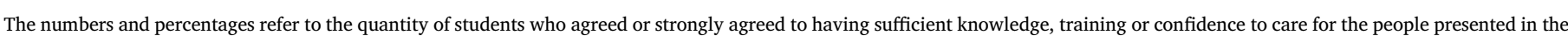
cases. The cases related to people with increasing comorbidity complexity from Case A to Case C.

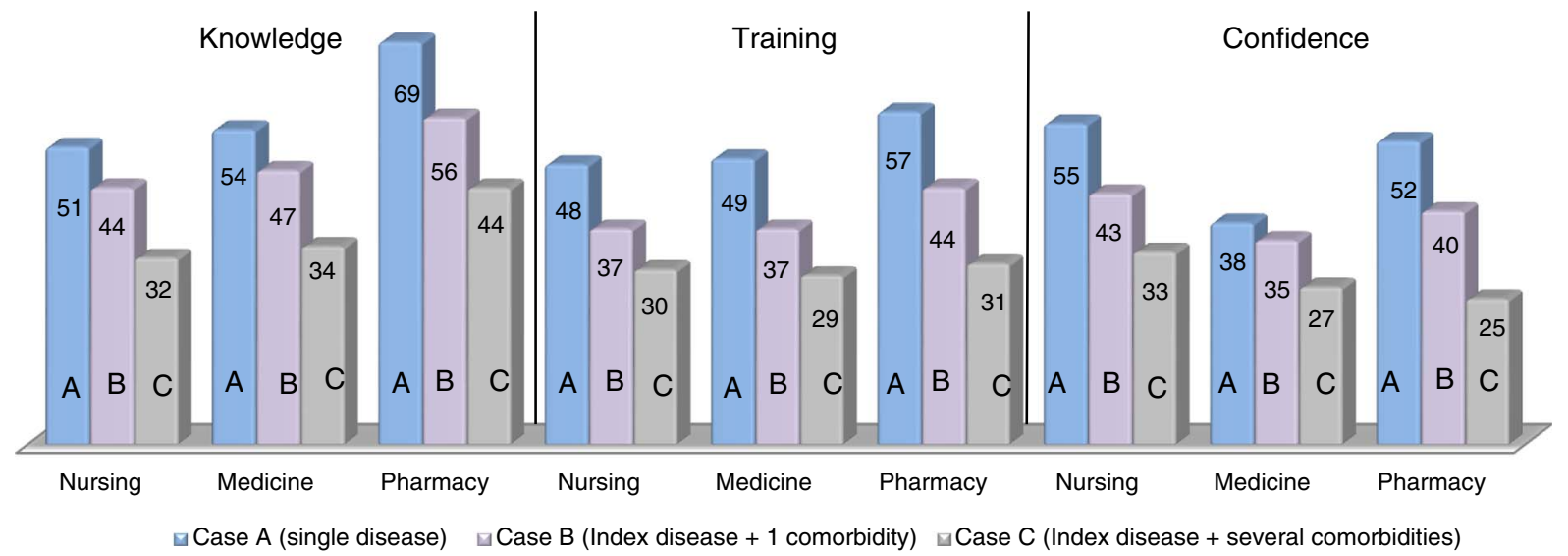

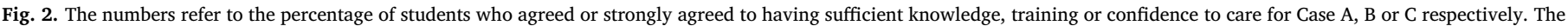
cases related to people with increasing comorbidity complexity from Case A to Case C.

would help them to learn about comorbidities (see Table 1), but none of the students had been taught specifically about comorbidities.

\subsection{Health Education Institution Workshops and Meetings}

Our multinational, multidisciplinary group of health education institution representatives found no explicit references to comorbidities in current health curricula (Table 3); however there was general agreement that multimorbidity would be covered in generic sessions on older people, frailty, community care, person-centred care, self-care, complex cases and health assessment approaches. Teaching about comorbidity in terms of the explicit implications of one condition for a patient's experience of another condition was ad hoc and at the discretion of individual tutors. Most surprising was the separation of physical and mental health across all programmes. Dementia was covered under care of older persons and anxiety and depression were covered in acute and chronic physiological care, but the full range of mental health conditions and their relationships with physiological health were not covered. A list of core comorbidity content was devised and discussed and amended until consensus was reached across the four countries and three disciplines (Table 3).

\subsection{The Framework}

The core comorbidity content list was used to develop a sixcomponent comorbidity education framework that could be used by lecturers and students, in class or remotely, to integrate comorbidity concepts with disease-specific teaching and learning. Our main objective was to produce a framework that included all the main comorbidity principles yet was simple enough to be useful at different stages of training and across different health disciplines. The six components of the framework are (i) conditions, (ii) context, (iii) corroboration, (iv) conflicts (v) communication and (vi) collaboration. We developed a simple version as an aide-memoire that presents a simple list of the six components, each with a trigger question. The trigger questions are intended to prompt students to think about the broader comorbidity context when considering the care of a person with an index condition. We also developed a more detailed version which includes supplements to the main trigger questions to encourage deeper exploration of the potential impact of comorbidity on care. The detailed version includes links to the wider curriculum in all three disciplines. These links were added to make it easier for students to see how to draw on their broader learning when dealing with comorbidity and to allow academics to integrate the framework into current curricula (Fig. 3 for the brief version and Supplementary File B for the detailed version).

Feedback on the draft framework was solicited from 254 English undergraduate nursing students; $89 \%$ reported that the framework was easy to understand and $92 \%$ felt that the framework would help them to learn about comorbidities. They commented on the need for better integration of social and healthcare systems to improve the care of people with learning disabilities and physiological or mental health comorbidities. They also suggested that including links to evidence and resources would be useful as would an electronic resource that could be used to transfer learning to practice. The framework was revised on the 
Table 3

HEI workshop and meetings: current and core comorbidity content.

\begin{tabular}{|c|c|}
\hline \multicolumn{2}{|l|}{ Current health curricula comorbidity content } \\
\hline Pathophysiology of individual conditions & Social and community health \\
\hline Patient complexity/older persons/frailty & Diagnostics and screening \\
\hline Long term diseases & Illness trajectories and impact \\
\hline Health conditions & History taking \\
\hline Physiological and mental health conditions & Clinical management skills \\
\hline Internal (general) medicine & Health assessment and examination \\
\hline Psychology and psychiatry & Epidemiology and public health \\
\hline Disability & Risk factors \\
\hline Nursing care and holistic principles & Emergency medicine \\
\hline Pharmacology, polypharmacy and drug interactions & Health theory and frameworks \\
\hline Acute and chronic care & Non-pharmacological interventions \\
\hline Health promotion & Inter-professional communication \\
\hline Primary and secondary prevention & \\
\hline
\end{tabular}

Core health curricula comorbidity content

Epidemiology of chronic diseases

Prevalence and incidence of chronic diseases and most common comorbidities

Chronic disease clusters and killer combinations

Shared documentation \& referral pathways

Assessment of potential conflicts between the patient's current or potential therapies and their individual preferences and health goals

Assessing patient's priorities for care

Inter professional communication

Professional autonomy

Pathophysiology of physical illness, diseases and their interrelations and or interactions

Shared risk factors, aetiology, pathophysiology of commonly co-occurring conditions

Interlinks between physical and mental health conditions

Autonomy and medical ethics and patient decision making

Assessment of a patient's aptitude for self-care maintenance and management given their multiple health problems

Confidentiality

Mental capacity and advocacy

Ageing and development of comorbidity

Pathophysiological, psychological, and environmental factors underlying mental health

Patient communication in complex disease

Shared risk factors, aetiology, pathophysiology of commonly co-occurring conditions

Patient empowerment

Breaking bad news

Assessment of patient's preferences for social, psychological, physical and spiritual well-being.

Polypharmacy, adverse reactions and contraindications

Public health and prevention of multimorbidity

Health promotion, primary and secondary prevention of index and comorbid conditions

Decision making in line with patient priorities

Inequalities and social deprivation and link with multimorbidity

Patient centred approaches

Self-care continuum from maintenance to management

Problem solving

Literature review of comorbidity evidence

Evidence synthesis

Critical appraisal of different levels of qualitative and quantitative evidence to include interpretation of quantitative data and generalisability.

Interpretation of statistics including relative and absolute risks

Patient education and information giving

Prognosis frameworks for individual and comorbid diseases

Assessment of care complexity

Care coordination

Principles of self-care in chronic and comorbid disease

End-of-life legal and ethical frameworks

The role of carers and carer fatigue, education and self-care skills

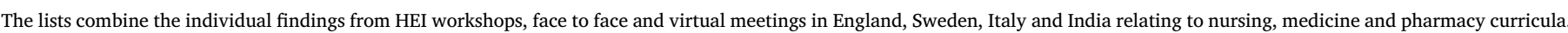

basis of student feedback and a review by health education institution academic members from the four countries involved in its development. A mobile application (downloadable from https://apps.nur.keele.ac. $\mathrm{uk} / \mathrm{media} / \mathrm{como} /$ ) was developed in response to student feedback. This presents the framework and lists key questions for the student to consider as well as providing links to resources, a tool for making exportable notes and a 'build your own case' section.

\section{Discussion}

Comorbidity is an important healthcare challenge, but is not yet covered explicitly or consistently in health education programmes across the world. Our survey showed that, although there were some differences between countries and disciplines, a high proportion of all healthcare students felt that they lacked sufficient knowledge, training and confidence to care for people with comorbidities, even in their final year of training. Current evidence and information from students and health education institutions were used to develop a simple framework for integrating comorbidity concepts into current healthcare curricula. 


\begin{tabular}{|l|l|l|}
\hline Conditions & $\checkmark \quad \begin{array}{l}\text { What are the } 3 \text { most common conditions (physiological or mental) that } \\
\text { might coexist with the index condition? }\end{array}$ \\
\hline Context & $\checkmark \quad \begin{array}{l}\text { How might the additional conditions influence the pathophysiology, } \\
\text { presentation and progression of the index condition? }\end{array}$ \\
\hline Corroboration & $\checkmark \quad \begin{array}{l}\text { What evidence or guidance exists for the index condition and for the } \\
\text { comorbidities? }\end{array}$ \\
\hline Conflicts & $\checkmark \quad \begin{array}{l}\text { Is there any common evidence across the different conditions? } \\
\text { pharmacological therapies required for the index condition and the } \\
\text { additional conditions? }\end{array}$ \\
\hline Collaboration & $\begin{array}{l}\text { What are the potential challenges for patient adherence and self-care } \\
\text { maintenance and management? }\end{array}$ \\
\hline Communication & $\checkmark \begin{array}{l}\text { How might the additional conditions influence the education and } \\
\text { information that the patient requires in order to manage their index } \\
\text { condition effectively? }\end{array}$ \\
\hline $\begin{array}{l}\text { Who within the multidisciplinary healthcare team may be required to } \\
\text { optimise the delivery of care to the patient with the multiple conditions? }\end{array}$ \\
\hline
\end{tabular}

Fig. 3. International comorbidity education framework (brief version).

\subsection{Current Knowledge, Training and Confidence}

Belief that they had sufficient knowledge, training and confidence to manage people with comorbidities was lowest amongst English nursing students and highest amongst Indian nursing students. The former result is perhaps not unexpected given that almost half the English nursing students were first-year students. The latter finding requires further exploration. It may reflect the distinct history of the nursing profession in India, where it has experienced more recent and accelerated change than in Europe (Tiwari et al., 2013). Despite reforms to nurse education since the establishment of the Indian Nursing Council in 1947, the nursing profession is still in its infancy in India and historical perceptions about the low social status of nurses and the explicit hierarchical relationship between the medical and nursing professions persist amongst nursing students (Garner et al., 2014). Indian nurses' lack of autonomy and their perception of their role as subservient to that of doctors may make them more confident about their ability to carry out tasks, because they are directed by doctors.

Pharmacy students reported being better equipped, in terms of knowledge and training, to deal with comorbidities than students of the other two professions. This is probably because they receive more training on multidrug prescribing, which is covered in all 4 years of their course. But although pharmacy students are used to dealing with patients taking multiple drugs, their confidence in prescribing is often lower in relation to more complex cases or when the patient's condition is more serious.

\subsection{Conditions and Context}

The lack of current curricula content dealing specifically with comorbidities and the high proportion of students wanting more comorbidity education were common to all countries and professions. A clear example of a gap in comorbidity learning was the segregation of mental and physical health in all curricula for all three disciplines. The frequency with which mental and physical ill-health co-occur
(Crawford et al., 2014; Collins et al., 2012) has led to a drive to improve the integration of mental and physical care (Walker and McAndrew, 2015). A separation between mental and physical health was evident in curricula for all disciplines, but was most evident in English nursing curricula, where students specialise in one or the other from the beginning of their training (Robinson and Griffiths, 2007). Yet despite generic training in the other European countries and in India, students and academics from all health disciplines still reported a separation of mental and physical health training at the point of delivery. The ICEF identifies the most common mental and physical comorbidities for specific index diseases. This has the potential to stimulate students to think about mental and physical health together, in a way that reflects the reality of people's lives.

\subsection{Corroboration, Conflicts and Communication}

Practising clinicians tend to work to clinical guidelines that are based on randomised controlled trials, which usually exclude people with comorbidities (Fortin et al., 2006). This means that there may be inadequate information to making decisions about management of complex cases (Grant et al., 2011). Clinicians find it challenging to involve patients in decision making and decide how to balance clinical priorities with the potential benefits and harms of multiple treatments (Fried et al., 2011). Patients want individualised care plans and care coordination (Bayliss et al., 2008). The ICEF makes it easier to introduce students of the health professions to the concept of joint consideration of disease-specific guidelines and evidence. This should help them to identify ways to integrate treatments and potential conflicts. It should also help students to prioritise in specific cases, to interpret the evidence in context of individual cases and to communicate complex information.

\subsection{Collaboration}

The complex nature of comorbidity means that multi-disciplinary 
working is needed to meet the care needs of people with comorbidity. Careful coordination and communication between professionals is required to prevent duplication, fragmentation or omissions of care (Coulter et al., 2013). A call has been made for the integration and organisation of professional roles in relation to the needs of people with comorbidities (Plochg et al., 2011) and there is a global push for interprofessional education (Gilbert et al., 2010). The ICEF should prompt students to consider the interplay between health professions in order to ensure that people with comorbidities receive safe and seamless care. The multi-disciplinary process used to develop the framework means that it should be readily applicable to inter-professional training.

\subsection{Implementation}

The comorbidity education framework should make it easier to integrate knowledge of comorbidity concepts into current curricula. However, as with any learning and teaching framework, the simple and structured approach does not in itself ensure that learning will take place. This requires the integration of such a framework into education programmes. The challenge for the future is to embed the framework into healthcare curricula and integrate it with a various pedagogical approaches, across different disciplines and different countries. This will require a systems approach to the integration of the comorbidity concepts into the broader curriculum (Jochems et al., 2004) and formal curricula mapping.

Comorbidity is a complex phenomenon and competence in this domain of care requires higher level learning, in the form of the synthesis of skills, knowledge and attitudes and the ability to transfer that integrated understanding to diverse clinical settings. This requires students to 'learn to learn', to problem-solve, to think critically and to self-assess - skills which fit best with a social constructivist approach to learning (Duane and Satre, 2014). The ICEF provides content and concepts which are student-centred and evidence-based. Constructive and collaborative learning are best facilitated by social and experiential learning using approaches such as problem- or case-based learning (Brandon and All, 2010). The ICEF can easily be applied to casework in any of the healthcare disciplines that is focused on a specific condition or health problem. It can be used to structure condition-specific lecture content or by students for individual or group case work. Pharmacy students already receive training on multidrug prescribing in the context of multiple conditions, but the ICEF can be used to consolidate and integrate content, in particular final-year material related to the planning of pharmaceutical care. This part of pharmacy courses deals with the wider assessment of pharmaceutical needs and care planning rather than just checking whether prescriptions are appropriate.

Case-based learning has been found to improve students' communication skills, problem-solving skills and motivation (Yoo and Park, 2015). In the context of case-based learning the ICEF is useful because it supports interactive, student-centred learning that draws on real-life cases to promote learning. The ICEF allows students to present cases and thus fosters the skills needed to solve real-life comorbidity problems and apply abstract knowledge to clinical practice. This provides an excellent method for students to consider how to plan and deliver care to people with comorbidities and to reflect on complex situations within a safe environment. The availability of the simple framework via an electronic application that enables students to make notes during clinical practice and reflect on their own cases, encourages consolidation of learning through practical application (Yardley et al., 2015).

Clearly, using the ICEF to support student-centred learning may pose a challenge to countries that in the process of making the transition from traditional teaching to problem-based learning (Nanda and Manjunatha, 2013). Although teaching in India is predominantly via didactic lectures, there is a move to introduce case-based learning into medical and nursing colleges. Using the ICEF should facilitate the transition to student-centred learning and person-focused group work.
The future plan will be to introduce interdisciplinary learning using the ICEF to explore cases from a multi-professional perspective.

\section{Limitations}

The ICEF was developed through a wide consultative process involving academics, clinicians and students from three health disciplines in four countries. However there are a number of limitations that must be acknowledged. The student and higher education institution samples involved in developing the ICEF were convenience samples. The student sample was heterogeneous with respect to level of training, which will have influenced their responses and the voluntary nature of the survey meant that there was a low response rate in some groups. Before the framework is implemented it should be tested in other countries and across a range of healthcare disciplines. Whilst medicine, nursing and pharmacy cover the largest proportion of health disciplines, other health-related disciplines such as physiotherapy and occupational therapy were not included in the development process. Further research is needed to determine whether the framework can be applied in these disciplines without adaptation. Likewise, involving Indian and Europeans in the development process should have ensured some cross-cultural validity, but there was wide variation in numbers, both across countries and across disciplines, and only four countries were involved in developing the framework. Implementation of the framework should take account of cultural differences in teaching and learning styles and empirical testing should be carried out beforehand to verify that the framework is applicable in the intended context.

\section{Conclusions}

Comorbidity education and training currently constitutes an important gap in healthcare curricula across the world. Undergraduates should be taught a more holistic approach to the management of multiple conditions to prepare them for 21st century care. We have developed an international comorbidity education framework (ICEF) that can easily be applied to current curricula, diverse teaching and learning modalities and diverse healthcare disciplines. It has the potential to realign professional competences with international healthcare priorities.

\section{Appendix A. Supplementary Data}

Supplementary data to this article can be found online at http://dx. doi.org/10.1016/j.nedt.2017.05.011.

\section{References}

American Geriatrics Society Expert Panel, 2012. Guiding principles for the care of older adults with multimorbidity: an approach for clinicians: American Geriatrics Society Expert Panel on the Care of Older Adults with Multimorbidity. J. Am. Geriatr. Soc. 60 (10), E1-E25.

Anderson, G., 2011. The latest disease burden challenge: people with multiple chronic conditions. In: Health Reform: Meeting the Challenge of Ageing and Multiple Morbidities. OECD Publishing. http://dx.doi.org/10.1787/9789264122314-en. Chapter 1.

Barnett, K., Mercer, S., Norbury, M., Watt, G., Wyke, S., et al., 2012. Epidemiology of multimorbidity and implications for health care, research, and medical education: a cross-sectional study. Lancet 380 (9836), 37-43.

Bayliss, E., Edwards, A., Steiner, J., Main, D., 2008. Processes of care desired by elderly patients with multimorbidities. Fam. Pract. 25 (4), 287-293.

Blythe, J., White, J., 2012. Role of the mental health nurse towards physical health care in serious mental illness: an integrative review of 10 years of UK literature. Int. J. Ment. Health Nurs. 21 (3), 193-201.

Boyd, C., Darer, J., Boult, C., Fried, L., Boult, L., et al., 2005. Clinical practice guidelines and quality of care for older patients with multiple comorbid diseases: implications for pay for performance. JAMA 294 (6), 716-724.

Brandon, A., All, A., 2010. Constructivism theory analysis and application to curricula. Nurs. Educ. Perspect. 31 (2), 89-92.

Burgers, J., Voerman, G., Grol, R., Faber, M., et al., 2010. Quality and coordination of care for patients with multiple conditions: results from an international survey of patient experience. Eval. Health Prof. 33 (3), 343-364. 
Castledine, G., 2006. Generalist versus specialist nursing practice. Br. J. Nurs. 15 (6), 347. Collins, E., Tranter, S., Irvine, F., 2012. The physical health of the seriously mentally ill: an overview of the literature. J. Psychiatr. Ment. Health Nurs. 19 (7), 638-646.

Coulter, A., Roberts, S., Dixon, A., 2013. Delivering Better Services for People With Longterm Conditions. The King's Fund, London.

Crawford, M., Jayakumar, S., Lemmey, S., Zalewska, K., Patel, M.X., et al., 2014. Assessment and treatment of physical health problems among people with schizophrenia: national cross-sectional study. Br. J. Psychiatry 205 (6), 473-477.

Department of Health, 2014. Comorbidities: A Framework of Principles for System-wide Action. Department of Health, London.

Duane, B., Satre, M., 2014. Utilizing constructivism learning theory in collaborative testing as a creative strategy to promote essential nursing skills. Nurse Educ. Today 34 (1), 31-34.

Ferguson, C., Inglis, S., Newton, P., Middleton, S., Macdonald, P., et al., 2016. Multimorbidity, frailty and self-care: important considerations in treatment with anticoagulation drugs. Outcomes of the AFASTER study. Eur. J. Cardiovasc. Nurs (1474515116642604. [Epub ahead of print]).

Fortin, M., Dionne, J., Pinho, G., Gignac, J., Almirall, J., et al., 2006. Randomized controlled trials: do they have external validity for patients with multiple comorbidities? Ann. Fam. Med. 4 (2), 104-108.

Fried, T., Tinetti, M., Iannone, L., 2011. Primary care clinicians' experiences with treatment decision making for older persons with multiple conditions. Arch. Intern. Med. 171 (1), 75-80.

Garner, S., Raj, L., Prater, L., Putturaj, M., 2014. Student nurses' perceived challenges of nursing in India. Int. Nurs. Rev. 61 (3), 389-397.

Gilbert, J., Yan, J., Hoffman, S., 2010. A WHO report: framework for action on interprofessional education and collaborative practice. J. Allied Health 39 (Suppl. 1), 196-197.

Grant, R., Ashburner, J., Hong, C., Chang, Y., Barry, M., et al., 2011. Defining patient complexity from the primary care physician's perspective: a cohort study. Ann. Intern. Med. 155 (12), 797-804.

Jochems, W., van Merriënboer, J., Koper, R., 2004. Integrated e-Learning - Implications for Pedagogy, Technology and Organisation. Routledge Falmer, London.

Lugtenberg, M., Burgers, J., Clancy, C., Westert, G., Schneider, E.C., 2011. Current guidelines have limited applicability to patients with comorbid conditions: systematic analysis of evidence-based guidelines. PLoS One 6 (10), e25987.

Nanda, B., Manjunatha, S., 2013. Indian medical students' perspectives on problem-based learning experiences in the undergraduate curriculum: one size does not fit all. J. Educ. Eval. Health Prof. 10, 11.

OECD, 2011. Health Reform: Meeting the Challenge of Ageing and Multimorbidities. Organisation for Economic Co-operation and Development.
Pati, S., Agrawal, S., Swain, S., Lee, J.T., Vellakkal, S., et al., 2014. Non communicable disease multimorbidity and associated health care utilization and expenditures in India: cross-sectional study. BMC Health Serv. Res. 14, 451.

Plochg, T., Klazinga, N., Schoenstein, M., Starfield, B., 2011. Reconfiguring health professionals in times of multimorbidity: eight recommendations for change. In: Health Reform: Meeting the Challenge of Ageing and Multiple Morbidities. OECD Publishing. http://dx.doi.org/10.1787/9789264122314-en. Chapter 4.

Robinson, S., Griffiths, P., 2007. Nursing Education and Regulation: International Profiles and Perspectives. Kings College, London.

Rushton, C., Kadam, U., 2014. Impact of non-cardiovascular disease comorbidity on cardiovascular disease symptom severity: a population-based study. Int. J. Cardiol. 175 (1), 154-161.

Rushton, C., Satchithananda, D., Jones, P., Kadam, U., 2015a. Non-cardiovascular comorbidity, severity and prognosis in non-selected heart failure populations: a systematic review and meta-analysis. Int. J. Cardiol. 196, 98-106.

Rushton, C., Green, J., Jaarsma, T., Walsh, P., Stromberg, A., et al., 2015b. The challenge of multimorbidity in nurse education: an international perspective. Nurse Educ. Today 35 (1), 288-292.

Salisbury, C., 2012. Multimorbidity: redesigning health care for people who use it. Lancet 380 (9836), 7-9.

Stewart, S., Riegel, B., Thompson, D., 2016. Addressing the conundrum of multimorbidity in heart failure: do we need a more strategic approach to improve health outcomes? Eur. J. Cardiovasc. Nurs. 15 (1), 4-7.

The King's Fund, 2013. Polypharmacy and Medicines Optimisation: Making It Safe and Sound. The King's Fund, London.

Tinetti, M., Bogardus, S., Agostini, J., 2004. Potential pitfalls of disease-specific guidelines for patients with multiple conditions. N. Engl. J. Med. 351 (27), 2870-2874.

Tiwari, R., Sharma, K., Zodpey, S., 2013. Situational analysis of nursing education and work force in India. Nurs. Outlook 61 (3), 129-136.

Van der Akker, M., Buntinx, F., Knottnerus, J., 1996. Comorbidity or multimorbidity: what's in a name? A review of the literature. Eur. J. Gen. Pract. 2 (2), 65-70.

Walker, S., McAndrew, S., 2015. The same but different: discussing the literature regarding mental health nurses' difficulty in meeting the physical health needs of service users, regardless of differing education programmes. J. Psychiatr. Ment. Health Nurs. 22 (8), 640-646.

Yardley, S., Cottrell, E., Rees, E., Protheroe, J., 2015. Modelling successful primary care for multimorbidity: a realist synthesis of successes and failures in concurrent learning and healthcare delivery. BMC Fam. Pract. 16, 23.

Yoo, M., Park, H., 2015. Effects of case-based learning on communication skills, problemsolving ability, and learning motivation in nursing students. Nurs. Health Sci. 17 (2), $166-172$. 